\title{
Further Evidence of the Relative Stability Evaluation of Lewis Acid Base Complexes
}

\author{
Salah Aldin Jassim Humadi, Leqaa Adnan Mohammed and Ekhlas Abdallah Hassan \\ Department of Chemistry, College of Science, University of Diyala, Diyala, Baquba-Iraq.
}

\begin{abstract}
Through Lewis acid-base complexation concept, interaction between three types of Lewis acid $\left(\mathrm{BCl}_{r}, \mathrm{AlCl}_{r}\right.$ and $\left.\mathrm{SiCl}_{\varepsilon}\right)$ as acceptors and many oxygen containing ether groups (such as dimethyl ether, ethyl methyl ether, cyclohexyl methyl ether, phenyl methyl ether, $1, r$ dioxane, $1, r$ dioxane and $1, \varepsilon$ dioxane) as donor ligands were evaluated based on several parameters including chemical potential, Global softness, HOMO- LUMO shapes and interaction energy of formed complexes.

Theoretical computational Density Functional Theory (DFT) and Hatree-Fock (HF) were used in addition to some empirical equations from literature to calculate the above mentioned parameters. This work proved that cyclohexyl methyl ether formed the most stable complex with silicon tetrachloride and the least stable complex being $\mathrm{BCl} r$ bond to dimetyl ether. This work provides further evidence that the relative Lewis acidity depends on the groups attached to the doner atom, and do not depend on the central atom of acid molecule.
\end{abstract}

Keywords: Lewis acid, complexation, interaction energy, donor, global softness, chemical potential.

\section{Introduction}

Metal-ligand bond strength depends on the value of interaction energy ( $\left.E_{\text {int }}\right)$. The bond strength and complexes stability increase as the value of interaction energy decreases (more negative value $)^{[1-r]}$.

Complexes formation and their relative stability can be estimated from the complex geometry. Bond shortening between ligand atom and vacant orbital acceptor reflects strong interaction with high stability of complex $^{[\xi, 0]}$.

It is found that the relative strength of donors depends on the nature of acceptor and vice versa, but many other factors may be involved. Hard Soft Acid Base (HSAB) classification is often used to rationalize some of strength difference ${ }^{\left[{ }^{\natural}\right]}$. Hard acid prefer hard base and soft acid prefer soft base. Hard hard interaction is fast because of large columbic attraction while a soft soft is fast because of large orbital overlap between HOMO (highest occupied molecular orbital) and LUMO (lowest unoccupied molecular orbital) ${ }^{[\mathrm{\gamma}]}$.

The interaction of a hard base with hard acid involves a low energy HOMO and a high energy $\mathrm{LUMO}^{[\wedge]}$. A hard acid is likely to be strongly solvated ${ }^{\left[{ }^{[}\right]}$.

According to HSAB, hard acids are positively charged on small atoms and have large gap between HOMO and LUMO energy, while soft acids are vice versa ${ }^{[1 \cdot]}$.

The strength of Lewis acid is a measure of its ability to attract a pair of electrons on molecule that behaves as Lewis base ${ }^{[1]}$. The relative strength of the Lewis acid depends on the nature of the atom and the groups attached to that atom ${ }^{[r]}$.

Density Functional Theory (DFT) considers the accurate computation theory between other methods which results in a good quality calculations for small and relatively large system, it demonstrates the relationship between the electron density and the total energy of the ground state, while Hartree Fock method (HF) provides only averaged correlation energy ${ }^{[r, 1, \varepsilon]}$.

This work aims to study the relative reactivity of Lewis acid base and the stability of formed complexes to determine if the sequence of acid strength depend on the nature of donor molecule or the nature of the central atom of acid molecule due to the tow famous theories addressed this field and to provide evidence to one of them.

\section{Calculation Methods}

Using ChemBiorn Ultra, HOMO, LUMO and optimization of Equilibrium Geometries of all studied molecules and their complexes have been calculated with two methods, density 
functional theory (DFT) $-B^{\mu} L Y P$ at $\left.\tau_{-} r\right) \mathrm{G}$

(d) basis set and Hartree-Fock (HF) at $r_{-} r{ }^{\prime} G$ (d).

Interaction energy is calculated by the following equations:

$$
E_{\text {int. }}=\Delta E_{\mathrm{v}}+\Delta E \mu
$$

All factors such as: $E_{\text {int., }} \Delta E_{\mathrm{v}}, \Delta E \mu \square \square \square$ chemical potential $(\mu)$ for $\square$ acid and base, global softness $(S)$ for acid and base, electronegativity $(\chi)$, the relation between Ionization energy (I) and Еномо, the relation between electron affinity (A) and $E_{\text {LUMO }}$ and finally $\lambda$ (as constant) where defined in references $\left[{ }^{10-19]}\right.$.

\section{Result and discussions}

Cyclohexyl methyl ether $>1, r$ dioxine $>1, \Sigma$ dioxine $>$ Ethyl methyl ether $>1, r$ dioxine $>$ Phenyl methyl ether (anisole) > Dimethyl ether.

and with DFT method, the following was obtained:

Cyclohexyl methyl ether $>1, \Gamma$ dioxine $>1$, s dioxine $>$ Ethyl methyl ether $>$ Dimethyl ether $>1, r$ dioxine $>$ Phenyl methyl ether (anisole)

Complexes of boron trichloride with the same donors have been determined too, by HF method, the order was determined as follows:

Cyclohexyl methyl ether $>1, r$ dioxine $>1, \varepsilon$ dioxine $>$ Phenyl methyl ether (anisole) $>$ Ethyl methyl ether $>1, r$ dioxine $>$ Dimethyl ether

and by DFT method, the order obey the following:

Cyclohexyl methyl ether $>1, r$ dioxine $>1, \varepsilon$ dioxine $>$ Phenyl methyl ether (anisole) $>$ Ethyl methyl ether $>1, r$ dioxine $>$ Dimethyl ether

Finally, the order of stability for silicon tetrachloride with ethers show another results especially in phenyl and dioxane derivatives, for HF the order being:

Cyclohexyl methyl ether $>$ Phenyl methyl ether (anisole) $>1, r$ dioxine $>1, r$ dioxine $>1, \varepsilon$ dioxine Ethyl methyl ether $>$ Ethyl methyl ether $>$ Dimethyl ether

and for DFT:

Cyclohexyl methyl ether $>$ Phenyl methyl ether (anisole) $>1, r$ dioxine $>1, r$ dioxine $>1, \varepsilon$ dioxine Ethyl methyl ether $>$ Ethyl methyl ether $>$ Dimethyl ether.

DFT and HF methods were used to determined HOMO, LUMO energy which represent the base line to calculate all other parameters studied in this work till the net values of interaction energy. It is known that DFT is more accurate than HF (which provides only averaged correlation energy). A comparison between the two methods was carried out for further confidence to evaluate the relative strength of Lewis 


\section{Journal of Al-Nahrain University}

Science

acid base interaction. The obtained results in Tables ( $(-r)$ show good matching between them except one case in Table (1) that disturb the sequence with respect to the position of dimethyl ether and both (phenyl methyl ether and $1, r$ dioxane), in any case DFT still the considerable method in such studies.

According to remarkably results obtained by DFT method due to the relative complexation ability between phenyl methyl ether as ligand with $\mathrm{AlCl}_{r}$ or $\mathrm{BCl}_{r}$ (both are approximately the same) and $\mathrm{SiCl}_{\varepsilon}$ as acceptors, it is clear that phenyl methyl ether occupies the last order in its ability to interact with $\mathrm{AlCl} r$ between the seven mentioned ligands, while with $\mathrm{SiCl}$ s it occupies the second order. The other possible explanation (in addition to interaction energy values) is the shape and size of HOMO lobe. HOMO shape is an indication of how the density of the electrons distributed in the molecule. It is clearly shown that the electron density (available on phenyl methyl ether Fig.( (a) transferred completely to $\mathrm{SiCl}_{\text {s }}$ site Fig.( ( b) while in the case of $\mathrm{AlCl} r$, partially shifting were appeared Fig.( ' c), this reflects that the ability of vacant $d$ orbitals available in the silicon atom has more tendency to accept electron cloud density in the phenyl group which behaves as pi - ligand toward silicon $\mathrm{d}$ orbitals, while $\mathrm{AlCl}_{r}$ vacant d orbitals do not have the same ability. By the same way, I, $r$ Dioxane also occupies the latest complexation order with respect to $\mathrm{AlCl}$, but with $\mathrm{SiCl}_{\varepsilon}$, the case is on the contrary, despite the lack of pi ligand, dioxane which contains two centers of electron density ( $r$ oxygen atoms) can be able to behave as bidentate molecule toward silicon vacant $\mathrm{d}$ orbitals which able to recover the further electron density from the oxygen but less than phenyl, see (Fig. $(r$ a,b,c)). Increasing $\mathrm{SiCl}_{\varepsilon}$ ability to accept further electron density is matching with (G. Michelangelo) ${ }^{\left[{ }^{r} \cdot\right]}$ who state that Lewis base coordination to $\mathrm{SiCl}_{\text {s }}$ activates Lewis acid.

There are two theories govern the order of Lewis acidity, the first theory gives definite concepts, for example, $\mathrm{BCl} r$ is absolutely stronger acid than $\mathrm{AlCl} r$ with out exception $\left[{ }^{[4, Y)]}\right.$, while the second theory refers that the relative orders of Lewis acidity will depend on the identify of the base used. According to this work, evidence has been provided to predominate the second theory and this conclusion clearly appears in Table ( $\& \Psi)$, which indicates that $\mathrm{BCl}_{r}$ is more acidic toward both phenyl methyl ether and $1, r$ dioxane, while $\mathrm{AlCl} r$ is more acidic toward other donors, so we provide further evidence that the second theory consider the preference one and there is no definite concepts about this case.

\section{Conclusion}

Cyclohexyl methyl ether is the strongest Lewis base (between the seven ligands) toward different studied acid due to its high donating ability as big electron release group. This work provides further evidence that the relative Lewis acidity depend on the nature of donor molecule and there is no definite opinion about this subject (as some references show). Both $\mathrm{Al}$ and $\mathrm{Si}$ have vacant $\mathrm{d}$ orbital, but $\mathrm{Si}$ in silicon tetrachloride has good ability to accept additional electon density especially from pi ligand such as phenyl group. Relatively, both HF and DFT give the same order except one case mentioned above. 

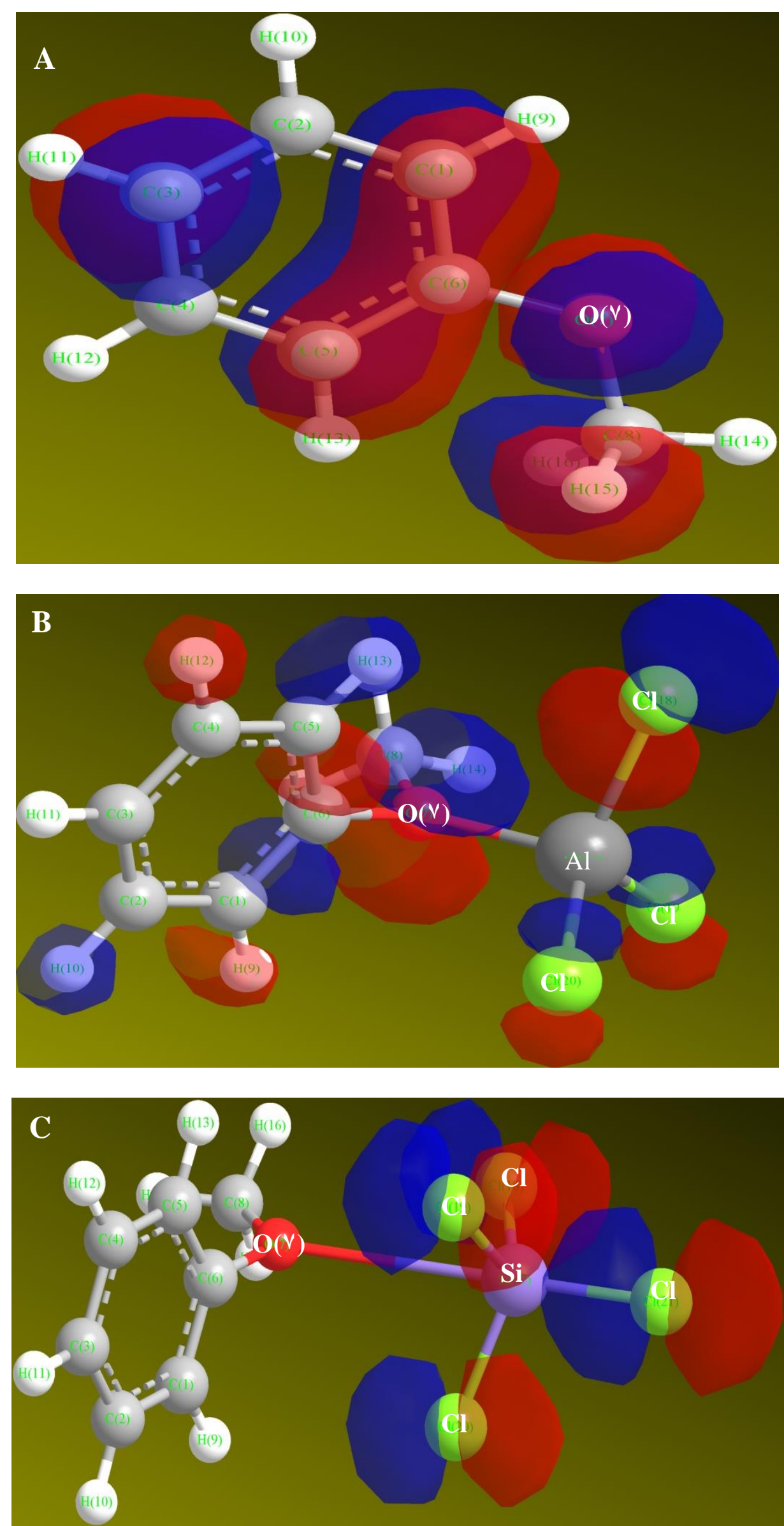

Fig.( (') The shape of HOMO lobe A) phenyl ethyl ether, B) phenyl ethyl ether bind with AlCl, C) phenyl ethyl ether bind with $\mathrm{SiCl}$. 

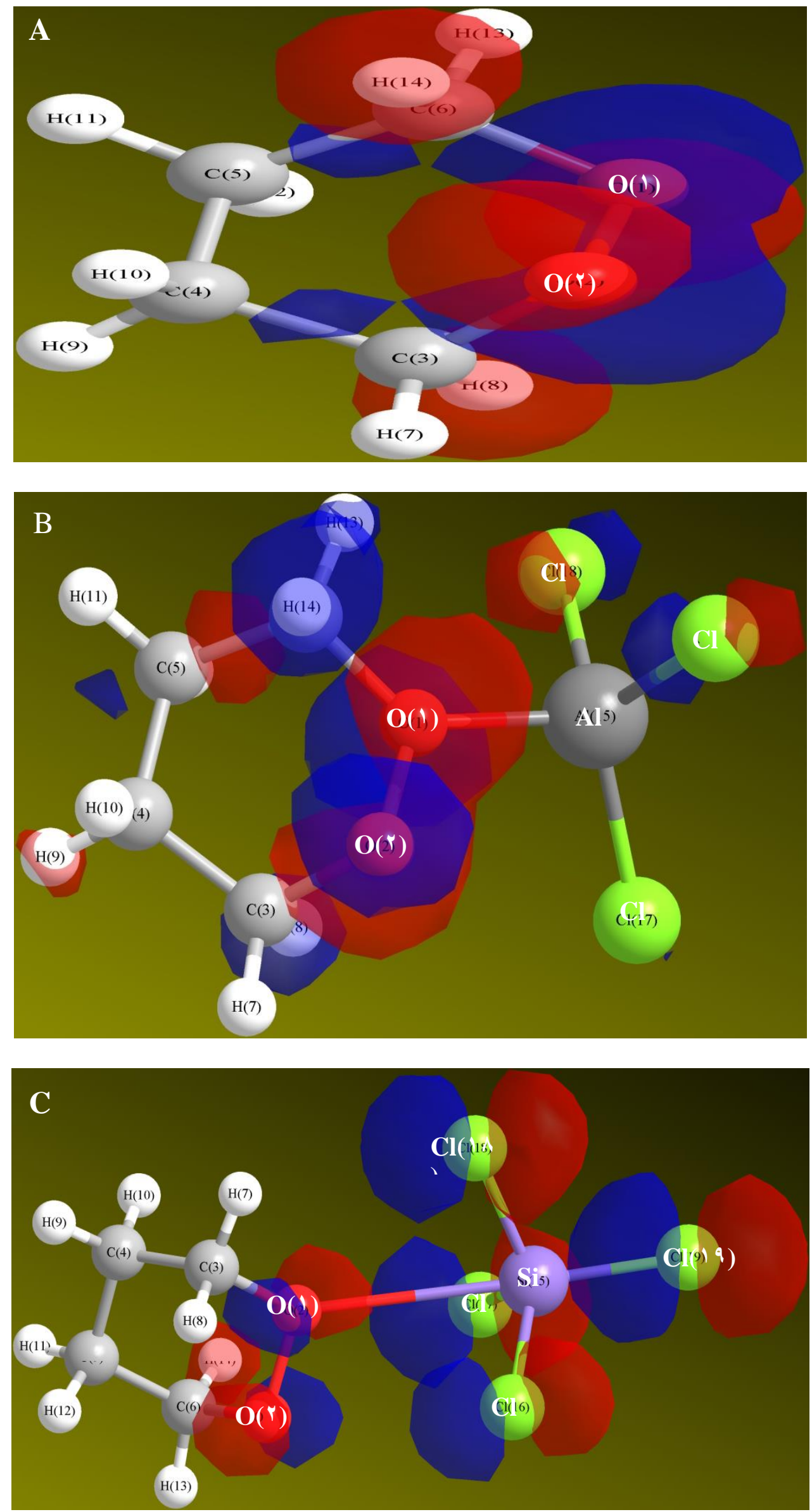

Fig.( (') The shape of HOMO lobe A) ', r Dioxane, B) ', r Dioxane bind with AlCl r, C) $1, r$ Dioxane bind with $\mathrm{SiCl}$. 
Salah Aldin Jassim Humadi 
Journal of Al-Nahrain University

Science

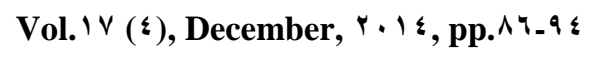


Salah Aldin Jassim Humadi 


\section{Journal of Al-Nahrain University \\ Science}

\section{References}

['] Singh, P. P.; Singh, R. K. and harma R. C.; "DFT based study of charge transfer and interaction energy between phenyl tin (IV) chlorides and derivatives of pyridine-Part II" J.Chem. Bio. Phy. Sci. Sec. A, Vol. r. No. ', 19-r $4, r .1 r$.

[ץ] Mishra, G.; Tanmya,V. and Singh, P. P.; "DFT based study of interaction of ortho, meta and para derivatives of pyridine and phenol derivatives with halides of titanium and silicon"; J. Chem. Pharm. Res., r(०): TV _ N), Y. Il.

[r] Tarek, M.; Gogary, E. and Koehler, G.; "Interaction of psoralens with DNA-bases (I). An ab initio quantum chemical, density functional theory and second-order MollerPlesset perturbational study: J. of Molec. Stru.: THEOCHEM $\left.\wedge \cdot \wedge, q v_{-}\right) \cdot q, r \cdots v$.

[₹] Ghosh, S.K.; and Ghosh, P.K.; Concepts and methods in modern theoretical Chemistry CRC Press, $r \cdot 1 r$.

[0] Norris, C. P.; "Trends In Surface Science Research", Nova Science Publishers, Inc, r... .

[`] Chatterjee, A. and Kawazoe, Y.; "Application of the Reactivity Index to Propose Intra and Intermolecular Reactivity in Metal Cluster Interaction over Oxide

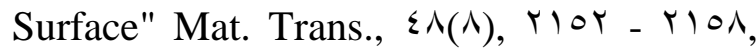
r.. V.

[`] Exandrov V. N.; Aldada, G. D. and Sloot, P. M.; "Computational Science - ICCS: 'th International Conference", Reading, UK, springer-Berlin, $\uparrow_{\cdots} \cdot \tau$.

[^] humadi, S.J.; "HOMO-LUMO, Infrared Frequencies and Molecular Geometry Comparison study of the Strength of Boron Trihalides Acidity using AMI Molecular Modeling" Iraq. J. of Scie., or(r), 1 r $0_{-} \mid r q$, r. Il.

[9] Agustí, L. and Feliu M., Computational Modeling of Homogeneous Catalysis, kluwer academic publisher, $r \ldots r$.

[1.] Cox, T.; "Instant Notes in Inorganic Chemistry", rnd ed., BIOS. Scientific Publisher, $\uparrow \ldots \varepsilon$.

[1'] Martins, L. F.; Silva, D.; Ochsner, A.; and Adams, D.; "Handbook of adhesion Technology", Springer, Heidelberg, r • 1$).$

[YY] Sangal, A.; "Advanced Organic Chemistry"; ${ }^{\text {st }}$ ed, Volume ', india, $Y \cdot 1 \cdot$.
[I ] Walker, J. D.; Enache, M. and Newman, M.; "Fundamentals QSARs for Metal Ions"; CRC press, r. $)^{\top}$.

[1 ] Dalton, D. R.; "Foundations of Organic Chemistry", ist ed., wiley \& sons Inc.,,+11

[10] House, J. and House, J. E.; "Inorganic Chemistry"; Elsevier Inc. London, ץ..^.

[17] Smith, M.; "Organic Chemistry: An Acid-Base Approach", CRC press, Taylor and francis group LLC, $Y \cdot 11$.

[IV] Halcrow, M. A.; "Spin -Crossover Materials: Properties and pplications"; Wiley, $r \cdot 1 r$.

[1^] Bant, G. and Clark, T.; "Drug Design Strategies: Computational Techniques and Applications", RSC publishing, UK, r. $r$ r.

[19] Smith, M. B. and March, J.; "March's Advanced Organic Chemistry: Reactions, Mechanisms, and Structure", wiley \& sons, r... $\mathrm{V}$.

$[r \cdot]$ Tressaud, A.; "Functionalized Inorganic Fluorides", wiley \&sons, UK., Y. ••.

[r I] Michelangelo, G. and Francisco, G.; "Catalytic Methods in Asymmetric Synthesis", wiley \& sons, New jersey, $r \cdot 11$.

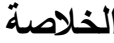

وفقـا لمفهوم المعقدات المتكونــة بـين حـوامض وقواعد

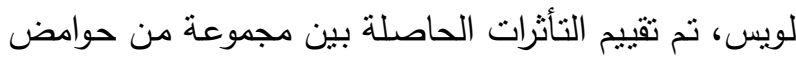
لـويس (r) الايثرات الحاوية على الاوكسجين مثل (ثنائي مثنيل ايثر واثيل

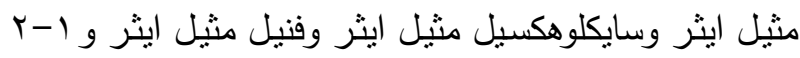

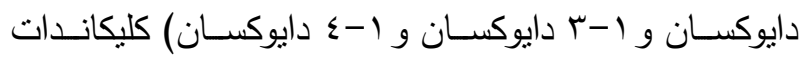

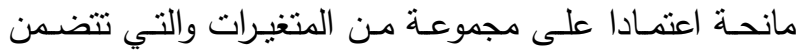

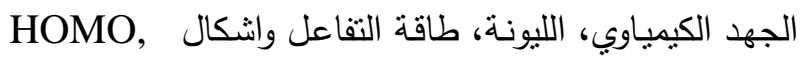

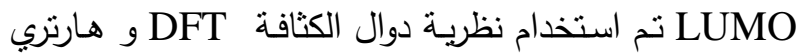

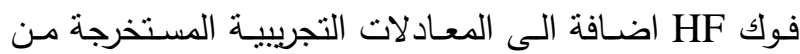

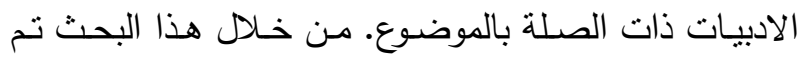

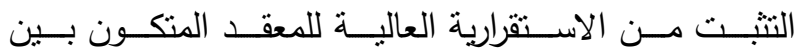

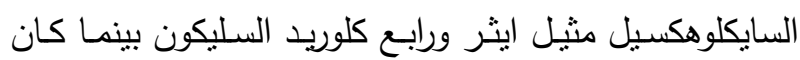
المعقد الاقل استقرارا هو المتكون بين ثثائي مثنيل ايثر وثالث

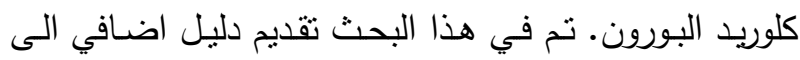
النظرية التي بموجبها ينم تقييم قوة حامض لويس على اساس

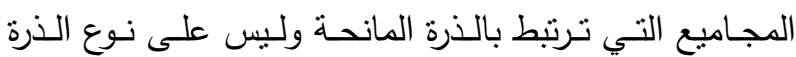

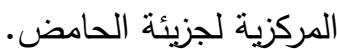

